\title{
KAJIAN LAJU ANGKUTAN SEDIMEN TOTAL PADA KANTONG LUMPUR BENDUNG AIR MUSI KEJALO
}

\author{
Anis Septia Rahayu' ${ }^{1)}$, Besperi ${ }^{2}$, Makmun Reza Razali ${ }^{3)}$ \\ ${ }^{122) 3)}$ Program Studi Teknik Sipil, Fakultas Teknik UNIB, Jl. W. R. Supratman, \\ Kandang Limun, Bengkulu 38371, Telp. (0736)344087 \\ email: inersia@unib.ac.id
}

\begin{abstract}
Abstrak
Bendung Air Musi Kejalo mengalami penurunan produktifitas, salah satu faktor penyebabnya adalah sedimentasi. Tujuan penelitian untuk mengetahui besar laju angkutan sedimen dari bendung yang masuk pada kantong lumpur menggunakan metode Shen and Hungs dan metode Meyer Petter Muller. Kemudian merencanakan dimensi kantong lumpur dari hasil laju sedimen yang telah didapatkan. Tahapan pelaksanaan penelitian yaitu pengujian sampel sedimen, pengukuran kecepatan aliran dan dimensi saluran kemudian dilakukan perhitungan dan analisis data. Hasil perhitungan menggunakan metode Shen and Hungs, didapatkan nilai debit laju sedimen pada kantong lumpur sebesar 0,1295 ton/hari, dan dengan metode Meyer Petter Muller sebesar 22,4966 ton/hari. Sehingga hasil debit laju sedimen metode Meyer Petter Muller yang digunakan untuk perencanaan dimensi kantong lumpur Bendung Air Musi Kejalo. Volume kantong lumpur Bendung Air Musi Kejalo adalah $120 \mathrm{~m}^{3}$. Dimensi kantong lumpur didapatkan panjang $61 \mathrm{~m}$, lebar $4 \mathrm{~m}$ dan kedalaman $1,3 \mathrm{~m}$. Kesimpulan penelitian ini adalah dengan dimensi kantong lumpur yang direncanakan berdasarkan volume sedimen yang didapat, kantong lumpur perlu dibilas selama 14 hari sekali agar sedimen tidak menumpuk pada kantong lumpur dan menggunakan konstruksi yaitu pasangan batu bulat dengan tipe saluran kantong lumpur berbentuk persegi dan tipe saluran induk berbentuk trapesium.
\end{abstract}

Kata kunci: sedimentasi, bendung, kantong lumpur

\begin{abstract}
Bendung Air MusiKejalo has decreased productivity,one of the contributing factors is sedimentation. The purpose of research is to know the massive rate of sediment transport from weir which enter in sand trap using method of Shen and Hungs and Meyer Petter Muller method. Then plot the dimensions of the sludge pouch from the resulting sediment rate.The stages of the research implementation are sediment sample test, flow velocity measurement and channel dimension then calculation and data analysis.The result of calculation using method of Shen and Hungs, got the value of sediment rate discharge at sand trap is 0,1295 ton / day, and by Meyer Petter Muller method equal to 22,4966 ton / day. So the result of sediment rate discharge Meyer Petter Muller method used for planning dimension sand trap of AirMusiKejaloWeir.Volume of sand trap Air MusiKejaloWeir is $120 \mathrm{m3}$. Dimensions of sand trap length $61 \mathrm{~m}$, width $4 \mathrm{~m}$ and depth of 1,3 $\mathrm{m}$. The conclusion of this study is that with the dimensions of planned sludge pockets based on the volume of sediment obtained, the sand trap should be rinsed for 14 days once so that the sediment does not accumulate in the sand trap and using a construction is pairs of round stone with type of sand trap is square and type of main drain is trapezoid.
\end{abstract}

Keywords: sediment, weir, sand trap 


\section{PENDAHULUAN}

Kabupaten Rejang Lebong memiliki bendung tetap yang dibangun oleh pemerintah berlokasi di Desa Cawang Lama, yaitu Bendung Air Musi Kejalo. Bendung Air Musi Kejalo ini digunakan untuk menaikkan elevasi muka air sebagai penyedia air dan sarana irigasi lahan pertanian bagi penduduk Desa Cawang Lama dan sekitarnya. Aspek pertanian merupakan salah satu bidang yang ditingkatkan karena sangat berpengaruh terhadap ketersediaan pangan bagi penduduk Desa Cawang Lama dan sekitarnya. Ketersediaan air berguna untuk pertumbuhan penduduk dan untuk megoptimalkan produksi pertanian.

Pada saat ini, Bendung Air Musi Kejalo mengalami penurunan produktifitas. Salah satu faktor yang menjadi penyebab menurunnya produktifitas Bendung Air Musi Kejalo adalah sedimentasi. Sedimentasi merupakan permasalahan yang sangat penting untuk diatasi, karena kerugian yang ditimbulkan oleh adanya proses sedimentasi jauh lebih besar dari pada manfaat yang diperoleh. Karena adanya sedimentasi yaitu proses terangkutnya partikel sedimen oleh gerakan air atau angin kemudian diikuti dengan pengendapan dapat menyebabkan pendangkalan sungai, bendung, dan saluran irigasi. Sehingga proses sedimentasi juga berlangsung dari bendung menuju saluran irigasi. Apabila musim kemarau tiba, penyedia air untuk saluran irigasi tidak berfungsi secara optimal dan saat musim penghujan, dapat menyebabkan banjir.

Pada penelitian ini bertujuan mengetahui besar laju angkutan sedimen yang masuk dari Bendung Air Musi Kejalo menuju kantong lumpur dan menghitung volume sedimen pada kantong lumpur Bendung Air Musi Kejalo. Kemudian dari hasil volume sedimen, direncanakan dimensi kantong lumpur sehingga dapat menampung besarnya sedimen yang masuk ke dalam jaringan irigasi pertanian pada Desa Cawang Lama, Kabupaten Rejang Lebong, Provinsi Bengkulu.

\section{METODE PENELITIAN}

Bagan alir penelitian dapat dilihat pada Lampiran 1. Pengumpulan data yang dilakukan meliputi data primer dan data sekunder.

1. Data primer

Data primer yang dibutuhkan berupa:

a. Kecepatan aliran

Untuk menentukan kecepatan aliran yaitu dengan menggunakan beberapa titik-titik vertikal menggunakan alat ukur arus (current meter) yang kemudian diukur kecepatan rata-ratanya pada penampang melintangnya.

b. Pengambilan sampel sedimen.

Untuk pengujian laboratorium analisis saringan, berat jenis dan konsentrasi sedimen layang. Sehingga mengetahui diameter butiran, berat jenis sedimen, dan konsentrasi sedimen layang.

2. Data sekunder

Data sekunder yang digunakan dalam penelitian ini antara lain:

a. Sumber studi literatur terhadap beberapa buku kumpulan jurnal serta memperoleh data dari instansi terkait.

b. Peta topografi yang didapat dari google earth untuk mencari kemiringan saluran pada kantong lumpur.

c. Data umum Bendung Air Musi Kejalo didapat dari BWS Sumatera VII.

Pelaksanaan penelitian dilakukan dengan beberapa tahapan penelitian. Tahapan pelaksanaan penelitian yaitu sebagai berikut:

1. Studi pustaka

Studi pustaka dilakukan dengan 
mengumpulkan jurnal-jurnal penelitian, membaca buku literatur, makalah dan skripsi yang berkaitan dengan penelitian yang akan dilakukan.

2. Survei pengambilan data primer Survei lapangan dilakukan dengan mengambil data:

a. Kecepatan aliran

Pengukuran kecepatan aliran menggunakan current metter menggunakan acuan SNI 8066:2015 tentang tata cara pengukuran debit aliran sungai dan saluran terbuka menggunakan alat ukur arus dan pelampung.

b. Dimensi saluran

Peneliti melakukan pengukuran langsung menggunakan tali untuk mengetahui lebar saluran, kedalaman saluran, luas penampang basah yang akan digunakan pada pengolahan data.

c. Pengambilan sampel sedimen dasar (bed load) dan sedimen layang (suspended load).
Sampel sedimen dasar masingmasing yang diambil 3 sampel dari Bendung Air Musi Kejalo. Dari pengujian sebelumnya, pengambilan sampel layang menggunakan botol sampel berupa botol plastik bekas air kemasan yang berdiameter $2,5 \mathrm{~cm}$ (mulut botol). Sampel sedimen layang masing-masing yang diambil 3 sampel dari kantong lumpur pada Bendung Air Musi Kejalo.

3. Pengumpulan Data Sekunder

a. Peta topografi.

b. Data umum Bendung Air Musi Kejalo.

4. Pengujian Sampel Sedimen di Laboratorium

Peneliti melakukan pengujian sampel sedimen di Workshop, Fakultas Teknik, Teknik Sipil, Universitas Bengkulu.

Pengujian sampel sedimen terdiri dari 3 pengujian, yaitu:

a. Analisis Saringan (SNI 03-19681990)

b. Berat Jenis Sedimen (SNI 1964:2008)

c. Pengolahan dan Analisis Data

\section{HASIL DAN PEMBAHASAN}

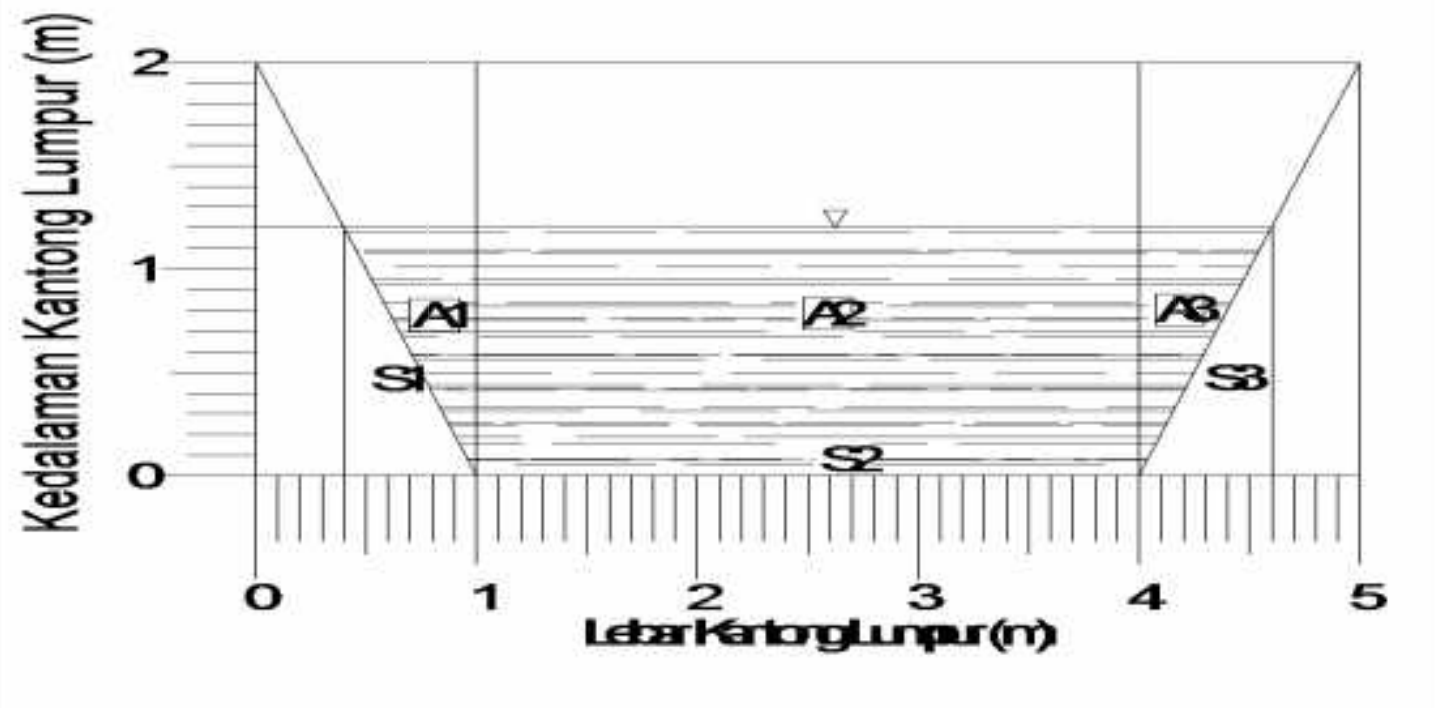

Gambar 1. Penampang Melintang Kantong Lumpur 
Jari-jari hidrolis

Berdasarkan hasil perhitungan luas penampan dan keliling penampang pada kantong lumpur maka didapatkan hasil perhitungan jari-jari hidrolis yaitu:
$\mathrm{R}=\frac{\mathrm{A}}{\mathrm{p}}$

$\mathrm{R}=\frac{4,32}{5,683}$

$\mathrm{R}=0,760 \mathrm{~m}$

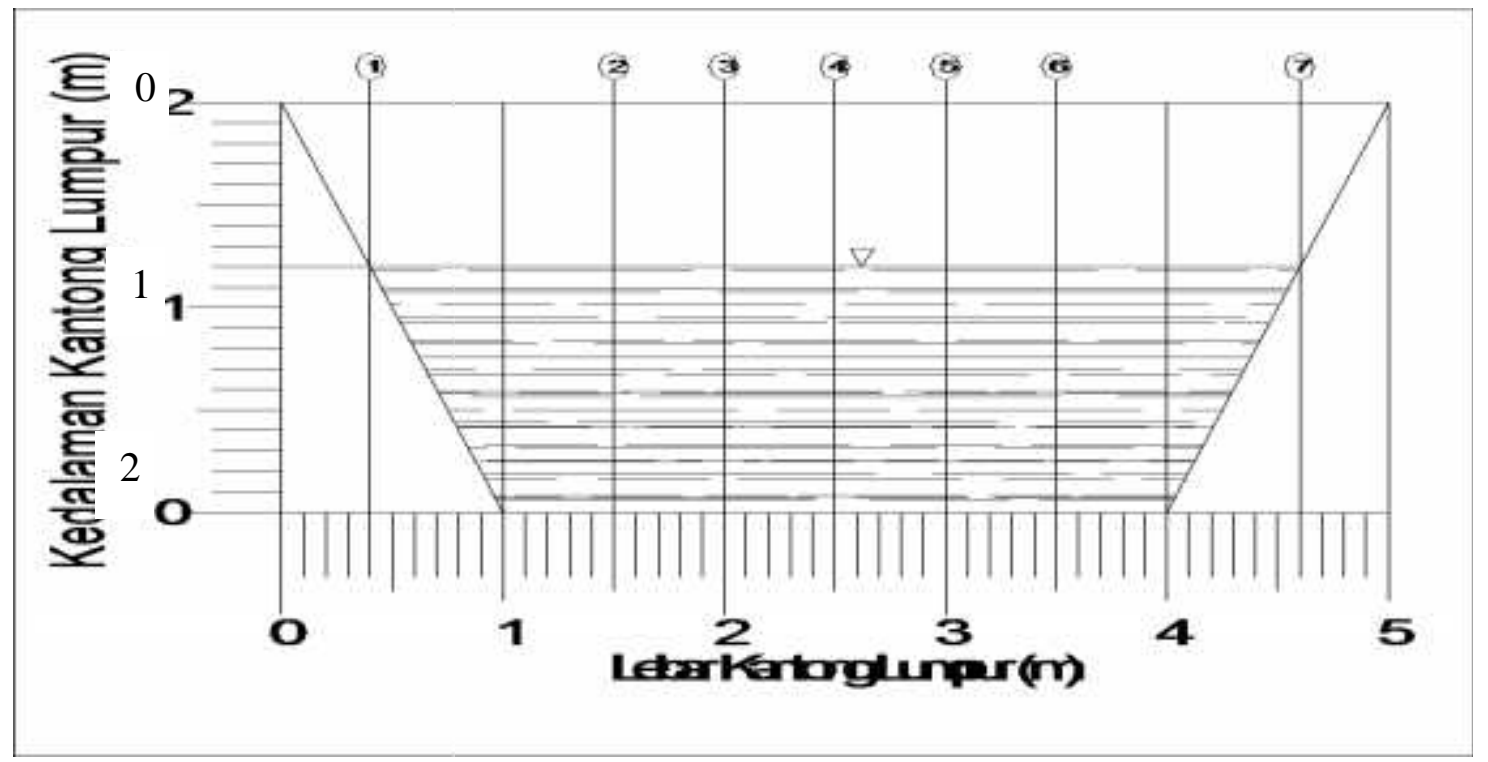

Gambar 2. Letak Pengukuran Kecepatan Aliran

Tabel 1. Pengolahan Data Kecepatan Arus dan Debit

\begin{tabular}{|c|c|c|c|c|c|c|c|c|c|c|c|}
\hline \multirow{2}{*}{ No } & \multirow{2}{*}{$\begin{array}{l}\text { Rai } \\
\text { (m) }\end{array}$} & \multirow{2}{*}{$\begin{array}{l}\text { Lebar } \\
\text { (m) }\end{array}$} & \multirow{2}{*}{$\begin{array}{l}\text { Dalam } \\
(\mathrm{m})\end{array}$} & \multirow{2}{*}{$\begin{array}{l}\text { Dalam } \\
\text { kincir }\end{array}$} & \multirow{2}{*}{$\begin{array}{l}\text { Jumlah } \\
\text { Putaran }\end{array}$} & \multirow{2}{*}{$\begin{array}{r}\text { Waktu } \\
\text { (detik) }\end{array}$} & \multirow{2}{*}{$\mathrm{n}$} & \multicolumn{2}{|c|}{$\begin{array}{l}\text { Kecepatan } \\
(\mathrm{m} / \mathrm{d})\end{array}$} & \multirow{2}{*}{$\begin{array}{l}\text { Luas } \\
\left(\mathrm{m}^{2}\right)\end{array}$} & \multirow{2}{*}{$\begin{array}{l}\text { Debit } \\
\left(\mathrm{m}^{3} / \mathrm{d}\right)\end{array}$} \\
\hline & & & & & & & & $\begin{array}{c}\text { Pada } \\
\text { titik }\end{array}$ & $\begin{array}{c}\text { Rata- } \\
\text { rata }\end{array}$ & & \\
\hline 1 & 0 & 0 & 0 & & 0 & \multicolumn{6}{|c|}{ Muka Air Kiri Jam 12.27} \\
\hline \multirow{2}{*}{2} & \multirow{2}{*}{1,5} & \multirow{2}{*}{1,1} & \multirow{2}{*}{1,2} & $0,2 \mathrm{~d}$ & 47 & 50 & 0,94 & 0,245 & \multirow{2}{*}{0,227} & \multirow{2}{*}{0,96} & \multirow{2}{*}{0,334} \\
\hline & & & & $0,8 \mathrm{~d}$ & 40 & 50 & 0,80 & 0,209 & & & \\
\hline \multirow{2}{*}{3} & \multirow{2}{*}{2} & \multirow{2}{*}{0,5} & \multirow{2}{*}{1,2} & $0,2 \mathrm{~d}$ & 84 & 50 & 1,68 & 0,434 & \multirow{2}{*}{0,391} & \multirow{2}{*}{0,60} & \multirow{2}{*}{0,209} \\
\hline & & & & $0,8 \mathrm{~d}$ & 67 & 50 & 1,34 & 0,347 & & & \\
\hline \multirow{2}{*}{4} & \multirow{2}{*}{2,5} & \multirow{2}{*}{0,5} & \multirow{2}{*}{1,2} & $0,2 \mathrm{~d}$ & 74 & 50 & 1,48 & 0,383 & \multirow{2}{*}{0,445} & \multirow{2}{*}{0,60} & \multirow{2}{*}{0,209} \\
\hline & & & & $0,8 \mathrm{~d}$ & 98 & 50 & 1,96 & 0,506 & & & \\
\hline \multirow{2}{*}{5} & \multirow{2}{*}{3} & 05 & 12 & $0,2 \mathrm{~d}$ & 107 & 50 & 2,14 & 0,552 & 0524 & 060 & ק 200 \\
\hline & & 0,5 & 1,2 & $0,8 \mathrm{~d}$ & 96 & 50 & 1,92 & 0,496 & $0,5 \angle 4$ & 0,00 & 0,209 \\
\hline & & & & $0,2 \mathrm{~d}$ & 45 & 50 & 0,90 & 0,234 & & & \\
\hline 6 & 3,5 & 0,5 & 1,2 & $0,8 \mathrm{~d}$ & 82 & 50 & 1,64 & 0,424 & 0,329 & 0,60 & 0,209 \\
\hline 7 & & & & $0,2 \mathrm{~d}$ & 35 & 50 & 0,70 & 0,183 & & & \\
\hline 7 & 4 & 1,1 & 1,2 & $0,8 \mathrm{~d}$ & 30 & 50 & 0,60 & 0,158 & 0,170 & 0,96 & 0,334 \\
\hline & & & Muk & Air Ka & Jam 12. & & & & 0,348 & & \\
\hline & & & & & & & & & & 4,320 & 1,502 \\
\hline
\end{tabular}


Tabel 2. Hasil Konsentrasi Sedimen Layang

\begin{tabular}{|c|c|c|c|c|c|}
\hline $\begin{array}{c}\text { Titik } \\
\text { Pengambilan }\end{array}$ & $\begin{array}{c}\text { Volume } \\
(\mathrm{ml})\end{array}$ & $\begin{array}{c}\text { Berat Sampel } \\
(\mathrm{gr})\end{array}$ & $\begin{array}{c}\text { Konsentrasi } \\
\text { Sedimen }(\mathrm{Cs}) \\
\mathrm{gr} / \mathrm{ml}\end{array}$ & $\begin{array}{c}\text { Konsentrasi } \\
\text { Sedimen }(\mathrm{Cs}) \\
\mathrm{gr} / \mathrm{ltr}\end{array}$ & $\begin{array}{c}\text { Konsentrasi } \\
\text { Sedimen } \\
(\mathrm{Cs}) \mathrm{mg} / \mathrm{ltr}\end{array}$ \\
\hline A & 600 & 0,1 & 0,0001667 & 0,167 & 166,667 \\
\hline B & 500 & 0,16 & 0,0003200 & 0,320 & 320,000 \\
\hline C & 600 & 0,02 & 0,0000333 & 0,033 & 33,333 \\
\hline \multicolumn{7}{|c|}{ Rata-rata } \\
\hline
\end{tabular}

\section{Perhitungan angkutan sedimen dengan formula Shen and Hungs}

Data yang diperlukan pada perhitungan yaitu:

1. Menghitung Kemiringan Saluran (Ss)

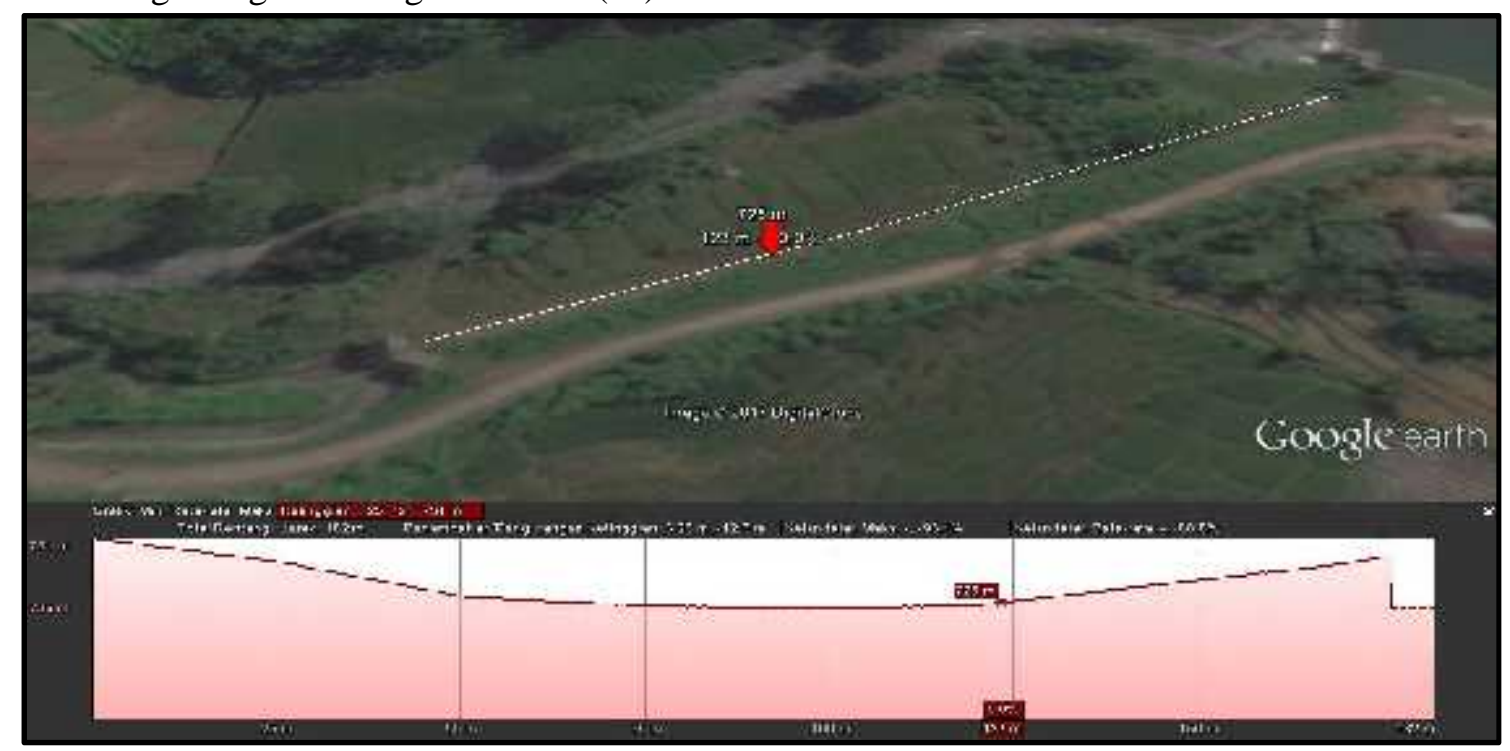

Sumber: Google Earth

Gambar 3. Profil Memanjang Ketinggian Kantong Lumpur

Sehingga kemiringan saluran $\left(\mathrm{S}_{\mathrm{s}}\right)$ pada saluran kantong lumpur Bendung Air Musi Kejalo yaitu:

Tinggi titik awal tinjauan $=731 \mathrm{mdpl}$ Tinggi titik akhir tinjauan $=725 \mathrm{mdpl}$ Jarak antar titik $\quad=182 \mathrm{~m}$ $\mathrm{S}_{\mathrm{s}}=-\frac{\text { Tinggit. akhir tinjau-Tinggi } \mathrm{t} . \text { awal tinjau }}{\text { Jarak antar titik }}$ $S_{\mathrm{s}}=\frac{725-731}{182}=-0,033$
1) Kecepatan aliran (v) $=0,348 \mathrm{~m} / \mathrm{d}$

2) Debit $(\mathrm{Q}) \quad=1,502 \mathrm{~m}^{3} / \mathrm{d}$

3) Diameter efektif $\left(\mathrm{d}_{50}\right)=0,59 \mathrm{~mm}$

Googleserth

2. Menghitung Kecepatan Jatuh $(\omega)$

Berdasarkan Gambar 4 grafik hubungan kecepatan jatuh dengan diameter dan temperatur, dalam buku Transport, Theory and Practice, 1996 Chih Ted Yang dengan menggunakan faktor permukaan 0,7 dikarenakan jenis sampel pasir, pada suhu $22^{\circ} \mathrm{C}$ dan $\mathrm{d}_{50}=0,59 \mathrm{~mm}$, maka diperoleh kecepatan jatuh $\omega=8 \mathrm{~cm} / \mathrm{dt}=0,08 \mathrm{~m} / \mathrm{dt}$. 


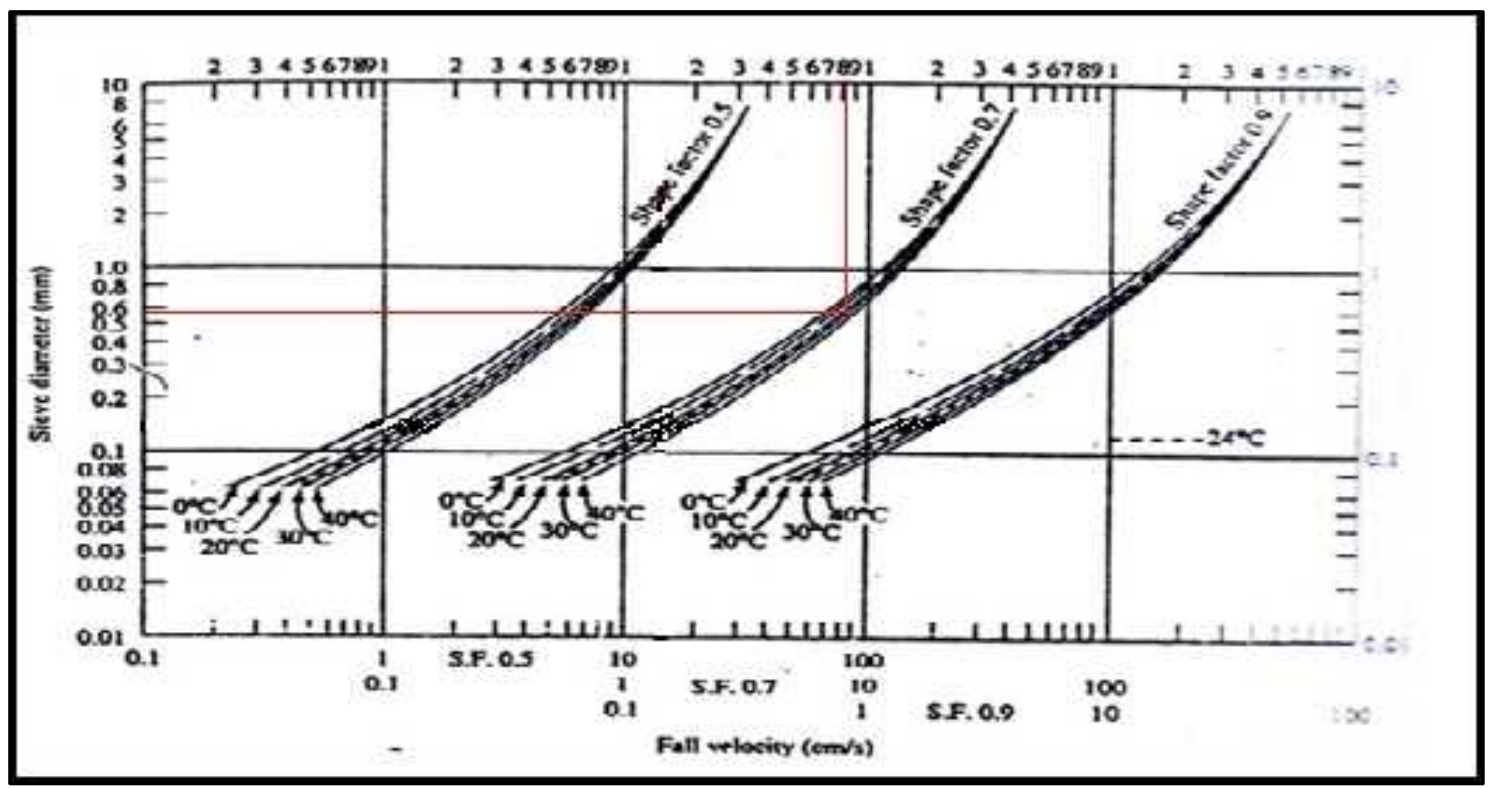

Sumber: Chih Thed Yang, 1996

Gambar 4. Grafik Hubungan Kecepatan Jatuh, Diameter dan Temperatur

3. Menghitung Parameter $\mathrm{Y}$

$$
\begin{aligned}
Y & =\left[\frac{V .5 s^{0,57}}{\omega^{0,37}}\right]^{0,0075} \\
& =\left[\frac{0,348,0,033^{0,57}}{0,08^{0,32}}\right]^{0,0075} \\
& =0,9837
\end{aligned}
$$

4. Menghitung Konsentrasi Sedimen $\left(\mathrm{C}_{\mathrm{t}}\right)$ $\log C_{t}=-107404,459+324214,747 * Y-$ $326309,589 * \mathrm{Y}^{2}+109503,872 * \mathrm{Y}^{3}$ $=-107404,459+324214,747$ $(0,9837)-326309,589(0,9837)^{2}$ $+109503,872(0,9837)^{3}$

$$
=-107404,459+318925,0021-
$$$$
315758,6044+104230,995
$$

$$
=2,933
$$

$$
\begin{aligned}
\mathrm{C}_{\mathrm{t}} & =10^{2,933}=856,992 \mathrm{ppm} \\
& =1 \mathrm{~g} / \mathrm{l}=1 \mathrm{~kg} / \mathrm{m}^{3}
\end{aligned}
$$

5. Menghitung Debit Sedimen Total Pada suhu $22^{\circ} \mathrm{C}$ didapatkan nilai berat jenis air berdasarkan Tabel 2.2 berat jenis untuk air murni terhadap macam-macam keadaan suhu (T), didapat dengan interpolasi yaitu $\gamma$ $=997,727 \mathrm{~kg} / \mathrm{m}^{3}$.

Jadi debit sedimen total $\left(Q_{t}\right)$ adalah:

$\mathrm{Q}_{\mathrm{t}} \quad=\frac{Q x C t}{10^{6}} x \gamma$

$$
\begin{aligned}
& ==\frac{1,502 \times 1}{10^{6}} \times 997,727 \\
& =0,0015 \mathrm{~kg} / \mathrm{dt} \\
& =0,1295 \mathrm{ton} / \mathrm{hari}
\end{aligned}
$$

Perhitungan angkutan sedimen dengan formula Meyer Petter Muller

Data yang diperlukan pada perhitungan yaitu:

1) Kecepatan aliran (v) $=0,348 \mathrm{~m} / \mathrm{dt}$

2) Kemiringan sungai $(\mathrm{Ss})=0,033$

3) Jari-jari hidrolis (R) $\quad=0,76 \mathrm{~m}$

4) $\operatorname{Debit}(\mathrm{Q}) \quad=1,502 \mathrm{~m}^{3} / \mathrm{dt}$

5) Diameter efektif $\left(D_{90}\right)=1,9 \mathrm{~mm}$

$$
=0,0019 \mathrm{~m}
$$

\section{Menghitung debit sedimen layang}

Dapat dilihat langsung pada Tabel 3, debit sedimen layang didapat menggunakan nilai konstanta, debit, dan konsentrasi sedimen melayang. 
Tabel 3. Hasil Debit Sedimen Layang

\begin{tabular}{|c|c|c|c|c|c|}
\hline No & $\begin{array}{c}\text { Titik } \\
\text { Pengambilan }\end{array}$ & Konstanta (k) & $\begin{array}{c}\text { Debit Rerata } \\
\left(\mathrm{m}^{3} / \mathrm{d}\right)\end{array}$ & $\begin{array}{c}\text { Konsentrasi } \\
\text { Sedimen } \\
\text { Melayang (Cs) } \\
(\mathrm{mg} / \mathrm{lt})\end{array}$ & $\begin{array}{c}\text { Debit Sedimen } \\
(\text { ton/hari) }\end{array}$ \\
\hline 1 & $\mathrm{~A}$ & 0,0864 & \multirow{2}{*}{1,502} & 166,667 & 21,626 \\
\hline 2 & $\mathrm{~B}$ & 0,0864 & 320,000 & 41,521 \\
\hline 3 & $\mathrm{C}$ & 0,0864 & & 33,333 & 4,325 \\
\hline \multicolumn{3}{|c|}{ Rata-rata } & 173,333 & 22,491 \\
\hline
\end{tabular}

$$
\text { Qs } \quad \begin{aligned}
&=\mathrm{k} \times \mathrm{C} \times \mathrm{Q} \\
&=0,0864 \times 173,333 \times 1,502 \\
&=22,491 \text { ton/hari }
\end{aligned}
$$

\section{Menghitung debit sedimen dasar}

1. Menghitung nilai kehilangan tenága akibat gesekan dengan butìran $(\mathrm{Kr})$

$$
\begin{aligned}
& \left(\frac{K_{s}}{K_{r}}\right)^{3 / 2}=\frac{S_{r}}{S_{s}}, S_{r}=S_{s} \times\left(\frac{K_{s}}{K_{r}}\right)^{3 / 2} \\
& K_{r}=\frac{26}{D 90^{\frac{3}{6}}} \\
& =\frac{26}{(0,0019)^{1 / 6}} \quad=73,878
\end{aligned}
$$

2. Menghitung nilai $\mathrm{Sr}$

$$
\begin{aligned}
S_{r} & =\frac{V^{2}}{K_{r} \times R^{4 / 3}} \\
& =\frac{0,348^{2}}{73,878 \times(0,76)^{4 / 3}} \\
& =0,00003192
\end{aligned}
$$

3. Menghitung nilai debit sedimen dasar

$$
\begin{aligned}
& \gamma\left(\frac{K_{S}}{K_{r}}\right)^{3 / 2} S_{S} \mathrm{R}=0,047\left(\gamma_{\mathrm{s}}-\gamma\right) \mathrm{d}+0,25 \\
& \rho^{1 / 3} \mathrm{q}_{\mathrm{b}}^{2 / 3}
\end{aligned}
$$

$(997,727)(0,00003192)(0,76)=0,047(2650$ $-997,727)(0,0003)+0,25(997,727 / 9,81)^{1 / 3}$ $(\mathrm{qb})^{2 / 3}$

$$
\begin{array}{ll}
0,024207 & =0,023297+1,166955 \mathrm{q}^{2 / 3} \\
0,00091 & =1,166955 \mathrm{q}^{2 / 3} \\
\mathrm{q}_{\mathrm{b}}^{2 / 3} & =0,00077949 \\
\mathrm{q}_{\mathrm{b}} & =(0,00077949)^{3 / 2} \\
\mathrm{q}_{\mathrm{b}} & =0,0000218 \mathrm{~kg} / \mathrm{dt} / \mathrm{m}
\end{array}
$$

$$
\begin{aligned}
Q_{b} & =q_{b} \times B \\
& =0,0000218 \times 3 \\
& =0,0000653 \mathrm{~kg} / \mathrm{dt} \\
& =0,005641 \text { ton } / \text { hari }
\end{aligned}
$$

4. Menghitung nilai debit sedimen total

$$
\begin{aligned}
\mathrm{Q}_{\mathrm{t}} & =\mathrm{Q}_{\mathrm{s}}+\mathrm{Q}_{\mathrm{b}} \\
& =22,491+0,005641 \\
& =22,4966 \text { ton } / \text { hari }
\end{aligned}
$$

\section{Perencanaan dimensi kantong lumpur}

Data yang diperlukan pada perhitungan yaitu:

1) Kecepatan aliran (v) $=0,348 \mathrm{~m} / \mathrm{dt}$

2) Kemiringan sungai $(\mathrm{Ss})=0,033$

3) Jari-jari hidrolis $(\mathrm{R}) \quad=0,76 \mathrm{~m}$

4) $\operatorname{Debit}(\mathrm{Q})=1,502 \mathrm{~m}^{3} / \mathrm{dt} \times 120 \%$

$$
=1,802 \mathrm{~m}^{3} / \mathrm{dt}
$$

1. Menghitung volume sedimen

Estimasi yang dipilih adalah Formula Meyer Petter Muller karena mengacu kepada estimasi yang lebih tinggi atau dengan kata lain estimasi angkutan sedimen yang terjadi pada saluran intake adalah 22,4966 ton/hari yang memiliki volume sedimen sebesar $\mathrm{Qt} / \gamma \mathrm{s}=22,4966 / 2,65=8,489 \mathrm{~m}^{3} / \mathrm{hari}$.

Jarak waktu pembilasan kantong lumpur, tergantung pada eksploitasi jaringan irigasi, banyaknya sedimen di sungai, luas tampungan serta tersedianya debit air sungai yang dibutuhkan untuk pembilasan. Untuk tujuan-tujuan perencanaan, biasanya diambil jarak waktu satu atau dua minggu (Kriteria 
Perencanaan - 02), $\mathrm{T}$ adalah lama pembilasan, diasumsikan 14 hari.

Volume kantong lumpur (V) bergantung pada jarak waktu (internal pembilasan)

$\mathrm{V}=$ Volume sedimen $\mathrm{x} \mathrm{T}$

$\mathrm{V}=8,489 \mathrm{~m}^{3} /$ hari $\mathrm{x} 14$ hari $=118,848 \mathrm{~m}^{3}$

Maka ambil volume kantong lumpur adalah $120 \mathrm{~m}^{3}$.
2. Mencari Nilai Kecepatan Endap (w)

Dalam kaitan dengan perencanaan kantong lumpur, ini berarti bahwa kapasitas angkutan sedimen pada bagian awal dari saluran primer penting artinya untuk ukuran partikel yang akan diendapkan. Biasanya ukuran partikel ini diambil $\varnothing 0,06-0,07 \mathrm{~mm}$ guna memperkecil kemiringan saluran primer.

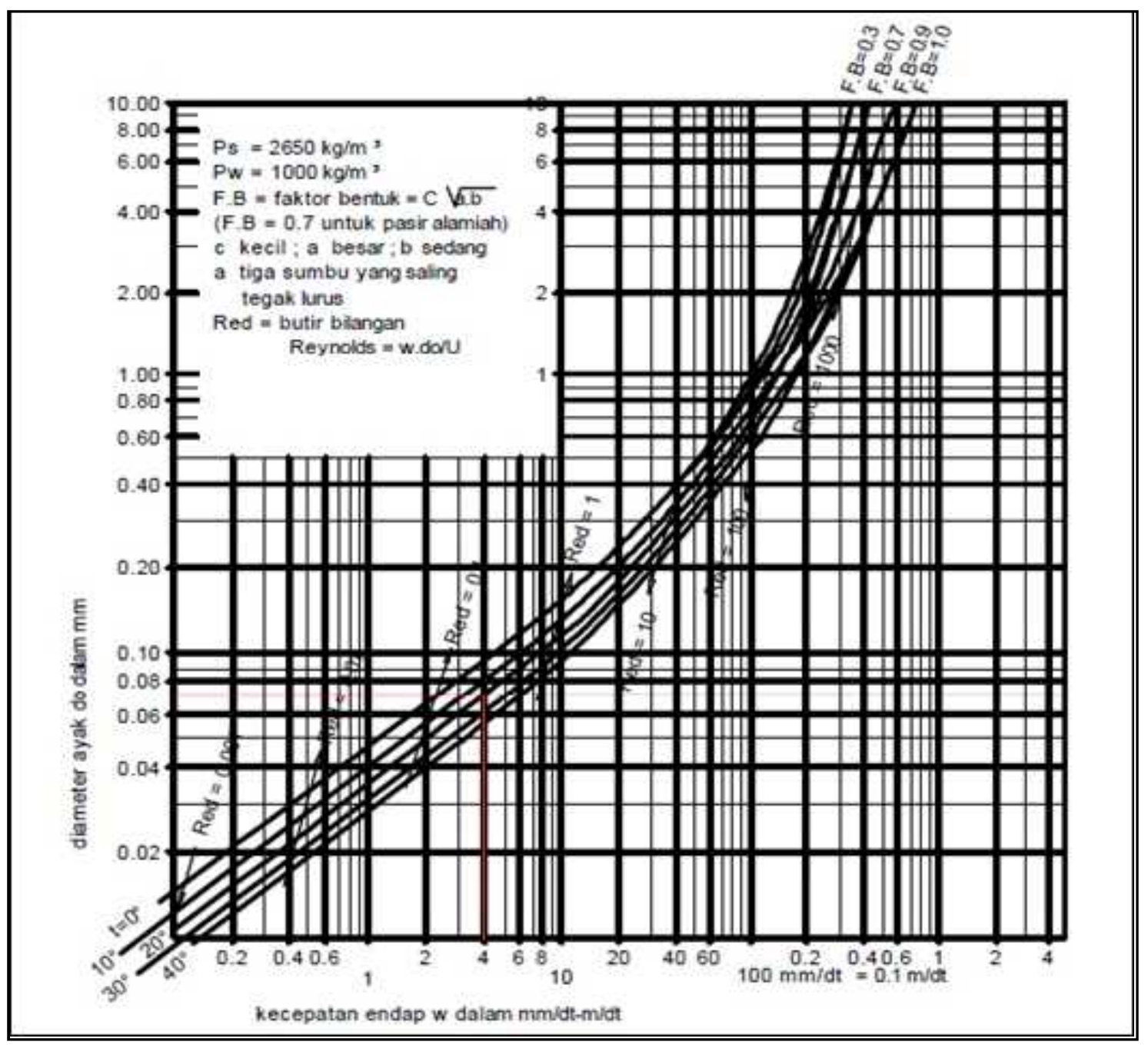

Sumber: Kriteria Perencanaan 02, Halaman 143

Gambar 5. Grafik Hubungan antara Diameter Saringan dan Kecepatan Endap

Pada suhu $22^{\circ} \mathrm{C}$ dengan diameter butiran 0,07 mm, maka kecepatan endap (w) berdasarkan grafik hubungan antara diameter saringan dan kecepatan endap untuk air tenang pada Gambar 6 diperoleh w $=0,004 \mathrm{~m} / \mathrm{dt}$.

3. Menghitung Estimasi Awal Dimensi Kantong Lumpur

$$
\mathrm{LB}=\frac{Q}{w}=\frac{1,802}{0,004}=450,535 \mathrm{~m}^{2}
$$

Karena L/B > 8 ( Kriteria Perencanaan - 02, halaman 167), dimensi kantong sebaiknya juga sesuai dengan kaidah bahwa L/B > 8, untuk mencegah agar aliran tidak meander di dalam kantong lumpur.

Maka dapat dihitung: 


$$
\begin{aligned}
& 8 B \times B=450,535 \mathrm{~m}^{2} \\
& \mathrm{~B}^{2}=375,446 / 8=56,317 \mathrm{~m}^{2} \\
& B<7,504 \mathrm{~m} \\
& L \quad \geq 8 \times 7,504 \mathrm{~m} \\
& L \quad \geq 60,035 \mathrm{~m}
\end{aligned}
$$

Jadi, Estimasi awal panjang kantong lumpur (L) adalah $\geq 60,035 \mathrm{~m}$ dan lebar saluran kantong lumpur (B) adalah < 7,504 $\mathrm{m}$

4. Perhitungan Saluran Induk

Perhitungan saluran induk Bendung Air Musi Kejalo menggunakan rumus Strickler.

Tabel 4. Free Board (W)

\begin{tabular}{|c|c|}
\hline $\begin{array}{c}\text { Q } \\
\left(\mathrm{m}^{3} / \mathrm{dt}\right)\end{array}$ & $\begin{array}{c}\mathrm{W} \\
(\mathrm{m})\end{array}$ \\
\hline$<0,5$ & 0,40 \\
\hline $0,5-1,5$ & 0,50 \\
\hline $1,5-5,0$ & 0,60 \\
\hline $5,0-10,0$ & 0,75 \\
\hline $10,0-15,0$ & 0,85 \\
\hline$>15,0$ & 1,00 \\
\hline
\end{tabular}

Sumber: Kriteria Perencanaan 03

Tabel 5. Koefisien Kekasaran Strickler terhadap Nilai Q

\begin{tabular}{|c|c|}
\hline $\begin{array}{c}\text { RencanaPengambilan } \\
\left(\mathrm{m}^{3} / \mathrm{dt}\right)\end{array}$ & $\mathrm{K}$ \\
\hline $\mathrm{Q}>10$ & 45 \\
\hline $5<\mathrm{Q}<10$ & 42,5 \\
\hline $1<\mathrm{Q}<5$ & 40 \\
\hline $\mathrm{Q}<1$ & 35 \\
\hline
\end{tabular}

Sumber: Kriteria Perencanaan 03

Berdasarkan Tabel 4 dan Tabel 5, untuk debit sebesar $1,502 \mathrm{~m}^{3} / \mathrm{dt}$ diperoleh free board (W) adalah 0,6 mdan koefisien strickler sebesar 40

a. Perhitungan luas penampang basah $\left(\mathrm{A}_{\mathrm{s}}\right)$

$$
\mathrm{A}_{\mathrm{s}} \quad=\frac{Q_{\mathrm{s}}}{\mathrm{v}}=\frac{1,502}{0,348}=4,320 \mathrm{~m}^{3} / \mathrm{dt}
$$

Lebar saluran $\left(b_{\mathrm{s}}\right)$ diambil $4 \mathrm{~m}$, kemiringan saluran 1:1,5. Didapat nilai $\mathrm{h}_{\mathrm{s}}$ adalah:
$\mathrm{A}_{\mathrm{s}} \quad=\left(\mathrm{b}_{\mathrm{s}}+\mathrm{m} . \mathrm{h}_{\mathrm{s}}\right) \mathrm{h}_{\mathrm{s}}$
$4,320=\left(4+1,5 . h_{s}\right) h_{s}$
$4,320=4 \mathrm{~h}_{\mathrm{s}}+1,5 \mathrm{~h}_{\mathrm{s}}{ }^{2}$
Dicoba $\mathrm{h}_{\mathrm{s}}=0,8247 \mathrm{~m}$
$4,320=4(0,8247)+1,5(0,8247)^{2}$
$4,320=4,320$.......OK
Nilai $h_{s}=0,8247 \mathrm{~m} \approx 1 \mathrm{~m}$

b. Perhitungan keliling basah saluran $\left(\mathrm{P}_{\mathrm{s}}\right)$

$$
\begin{aligned}
\mathrm{P}_{\mathrm{s}} & =\mathrm{b}_{\mathrm{s}}+2 . \mathrm{h}_{\mathrm{s}} \sqrt{\mathrm{m}^{2}+1} \\
& =4+2 \times 1 \sqrt{1,5^{2}+1} \\
& -7,6055 \mathrm{~m}
\end{aligned}
$$

c. Perhitungan jari-jari hidrolis saluran $\left(\mathrm{R}_{\mathrm{s}}\right)$

$R_{s}=\frac{A_{5}}{P}=\frac{4,320}{7,6055}=0,5675 \mathrm{~m}$

d. Perhitungan kemiringan saluran

$$
\begin{aligned}
I_{s} & =\left[\frac{v_{i}}{k \cdot R^{2 / 3}}\right]^{2} \\
& =\left[\frac{0,348}{40 \cdot 0,5675^{2 / 3}}\right]^{2} \\
& =0,00003556
\end{aligned}
$$

Jadi, dimensi saluran induk yaitu:

$$
\begin{aligned}
\mathrm{b}_{\mathrm{s}} & =4 \text { meter } \\
\mathrm{h}_{\mathrm{s}} & =1 \text { meter } \\
\mathrm{m} & =1: 1,5 \\
\mathrm{~F} & =0,6 \mathrm{~m}
\end{aligned}
$$

5. Perhitungan kantong lumpur

Perencanaan kantong lumpur berdasarkan kebutuhan mengalirkan debit rencana dan penampungan sedimen dalam jangka waktu dan kapasitas tertentu. Kantong lumpur berada pada bagian bawah saluran pembawa.

Data yang diperlukan pada perhitungan:

$\mathrm{Q}_{\mathrm{n}} \quad=1,502 \mathrm{~m}^{3} / \mathrm{dt} \times 120 \%$

$$
=1,802 \mathrm{~m}^{3} / \mathrm{dt}
$$

Kecepatan aliran $(\mathrm{V}) \quad=0,348 \mathrm{~m} / \mathrm{dt}$

Lebar kantong lumpur $(b)=4$ meter. 
a. Perhitungan luas penampang basah kantong lumpur $\left(\Lambda_{\mathrm{tn}_{\mathrm{n}}}\right)$

$$
\begin{aligned}
\mathrm{A}_{\mathrm{n}} & =\frac{\mathrm{Q}_{\mathrm{n}}}{\mathrm{V}} \\
& =\frac{1,802}{0,348} \\
& =5,179 \mathrm{~m}^{2}
\end{aligned}
$$

b. Mencari tinggi kantong lumpur $\left(\mathrm{h}_{\mathrm{n}}\right)$

$\mathrm{A}_{\mathrm{n}} \quad=\mathrm{b} \cdot \mathrm{h}_{\mathrm{n}}$

$5,179=4 . \mathrm{h}_{\mathrm{n}}$

$\mathrm{h}_{\mathrm{n}} \quad=1,295 \mathrm{~m} \approx 1,3 \mathrm{~m}$

c. Perhitungan keliling basah kantong lumpur $\left(\mathrm{P}_{\mathrm{n}}\right)$

$$
\begin{aligned}
\mathrm{P}_{\mathrm{n}} & =\mathrm{b}+(2 \times \mathrm{hn}) \\
& =4+(2 \times 1,3) \\
& =6,6 \text { meter }
\end{aligned}
$$

d. Perhitungan jari-jari hidrolis kantong lumpur $\left(R_{n}\right)$

$$
\begin{aligned}
\mathrm{R}_{\mathrm{n}} & =\frac{A_{n}}{\mathrm{P}_{n}} \\
& =\frac{5,179}{6,6} \\
& =0,785 \text { meter }
\end{aligned}
$$

e. Perhitungan kemiringan kantong lumpur $\left(I_{n}\right)$

$\mathrm{V}_{\mathrm{n}}=\mathrm{K}_{\mathrm{s}} \times R_{n^{\frac{2}{3}}} \times l_{n^{\frac{1}{2}}}$

Tabel 6.Koefisien Kekasaran Strickler

\begin{tabular}{|c|c|}
\hline Pemakaian & Koefisien \\
\hline Pasangan Batu & 60 \\
\hline Pasangan Beton & 70 \\
\hline Pasang Tanah & $35-45$ \\
\hline Ferrocemen & 70 \\
\hline
\end{tabular}

Sumber: Kriteria Perencanaan 03, 1986
Ks adalah kocfisien Strickler untuk pasangan batu sebesar 60 .

$$
\begin{aligned}
I_{n} & =\frac{V_{n}^{2}}{\left(K_{\mathrm{S}} \times \mathrm{R}_{\mathrm{n}}^{\frac{2}{3}}\right)^{2}} \\
& =\frac{0,348^{2}}{\left(60 \times 0,785^{\frac{2}{3}}\right)^{2}}=0,0000465
\end{aligned}
$$

Untuk bahan endapan pasir kasar dengan $\varnothing$ 0,06 - 0,07 mm ditetapkan kecepatan aliran di kantong lumpur pada saat pembilasan adalah $1,50 \mathrm{~m} / \mathrm{dt}$.Agar pengambilan dapat berjalan dengan baik, maka kecepatan aliran harus tetap subkritis atau Fr $\leq 1$.

$$
\begin{aligned}
\mathrm{F}_{\mathrm{r}} & =\frac{V_{\mathrm{s}}}{\sqrt{\mathrm{g \times h_{5 }}}} \\
& =\frac{1,5}{\sqrt{9,81 \times 1,3}} \\
& =0,42=1 \ldots \ldots \ldots . \mathrm{OK}
\end{aligned}
$$

6. Perhitungan volume kantong lumpur

Volume kantong lumpur yang diperlukan adalah $120 \mathrm{~m}^{3}$

$\mathrm{V}=\mathrm{h}_{\mathrm{s}} \times \mathrm{b} \times \mathrm{L}+0,5 \times \mathrm{I}_{\mathrm{n}} \times \mathrm{L}^{2} \times \mathrm{b}$

$$
\begin{aligned}
& 120=1,3 \times 4 \times \mathrm{L}+0,5 \times 0,0000465 \\
& \mathrm{x} \mathrm{L}^{2} \times 4 \\
& 120=5,2 \mathrm{~L}+0,000093 \mathrm{~L}^{2} \\
& \mathrm{~L}=23,07 \mathrm{~m}
\end{aligned}
$$

Karena estimasi awal panjang kantong lumpur $\geq 60,035 \mathrm{~m}$, maka diambil panjang kantong lumpur $60,035 \mathrm{~m} \approx 61 \mathrm{~m}$. Sehingga didapatkan dimensi saluran kantong lumpur yaitu:

$$
\begin{aligned}
\mathrm{m}=\mathrm{I}_{\mathrm{n}} \mathrm{x} \mathrm{L} & =0,0000465 \mathrm{x} 61 \\
& =0,002835 \mathrm{~m} \\
& =0,2835 \mathrm{~cm} \approx 10 \mathrm{~cm}
\end{aligned}
$$

$\mathrm{b}=4$ meter

$\mathrm{h}_{\mathrm{n}}=1,3$ meter

$\mathrm{L}=61 \mathrm{~m}$ 


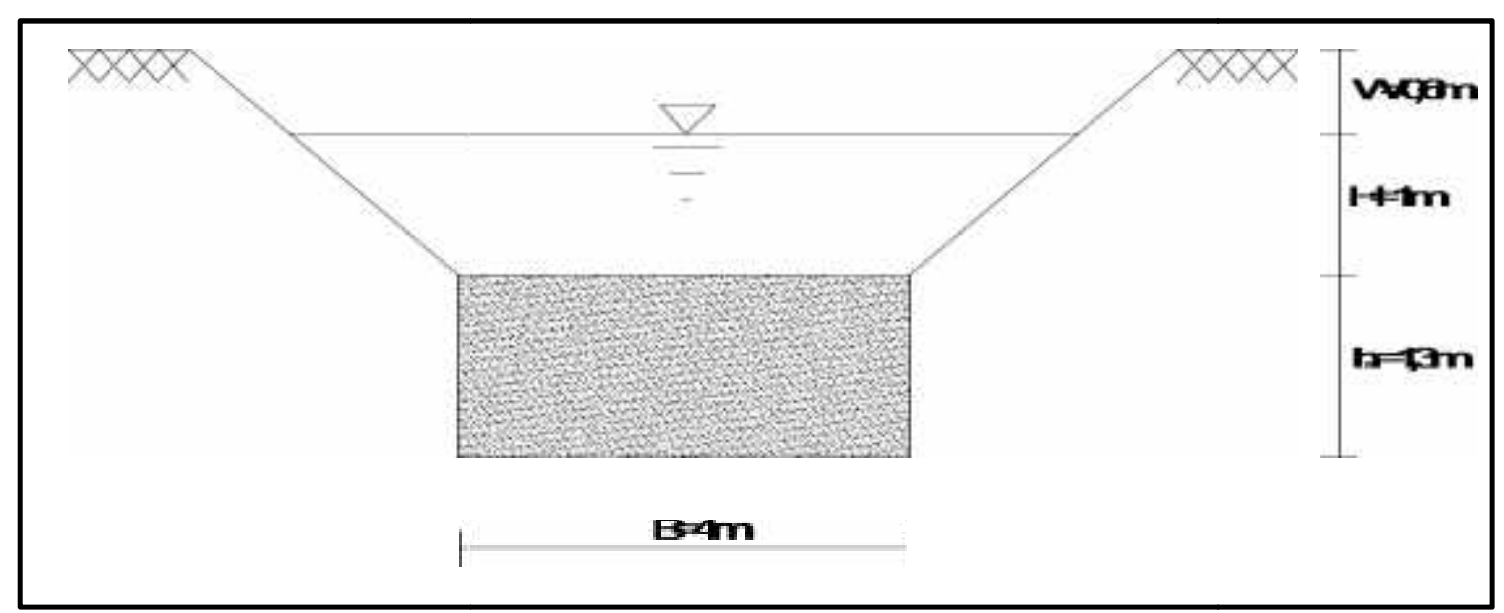

Gambar 6. Potongan Melintang Kantong Lumpur

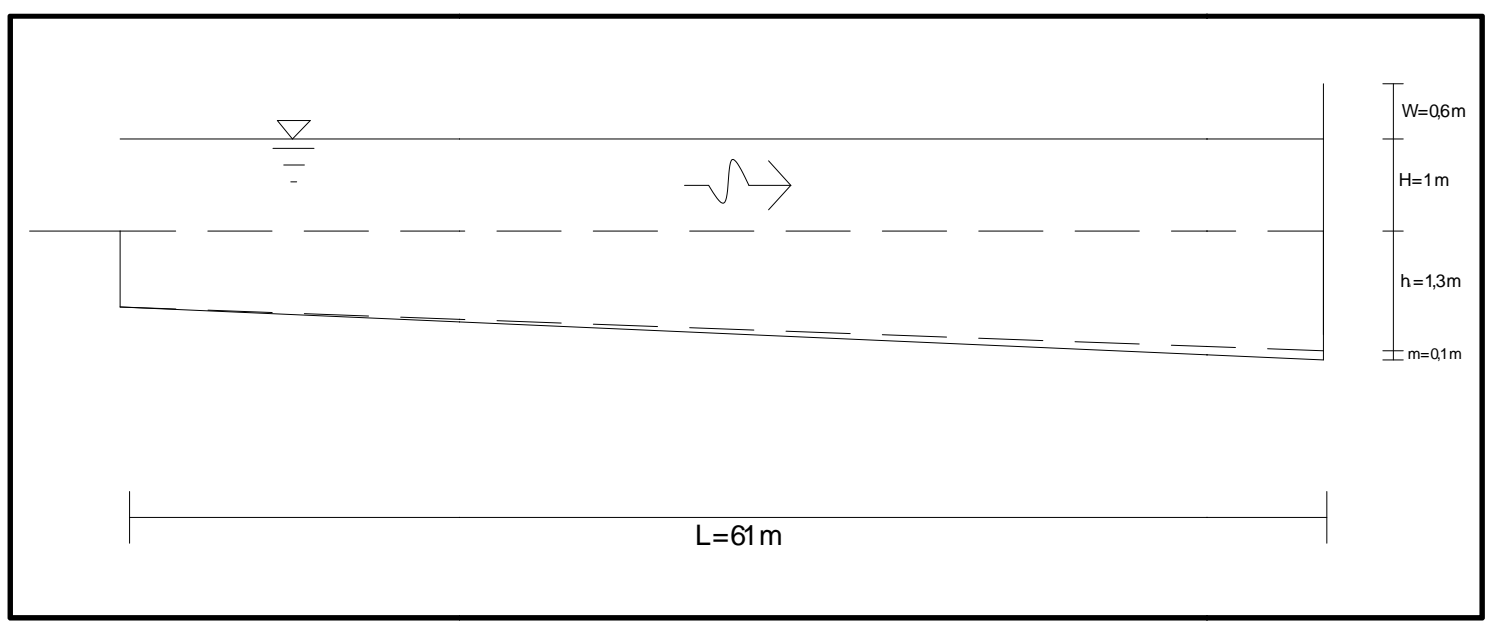

Gambar 7. Potongan Memanjang Kantong Lumpur

Dari hasil besar laju sedimen yang masuk ke kantong lumpur Bendung Air Musi Kejalo dan kemudian menghitung volume sedimen di kantong lumpur, maka di dapatkan dimensi kantong lumpur seperti pada Gambar 7. dan Gambar 8. Perhitungan laju sedimen menggunakan Metode Meyer Peter Muller dengan perencanaan kantong lumpur harus dibilas selama 14 hari sekali dan menggunakan konstruksi yaitu pasangan batu bulat dengan tipe saluran kantong lumpur berbentuk persegi dan tipe saluran induk berbentuk trapesium.

\section{KESIMPULAN}

Berdasarkan hasil analisis pada penelitian laju angkutan sedimen pada kantong lumpur pada Bendung Air Musi Kejalo dapat disimpulkan sebagai berikut:

1. Hasil analisis laju angkutan sedimen menggunakan etode Shen and Hungs didapatkan nilai debit sedimen dasar total adalah 0,1295 ton/hari dan metode Meyer Peter Muller didapatkan nilai debit sedimen dasar dan layang total adalah 22,4966 ton/hari. Sehingga untuk perencanaan kantong lumpur menggunakan nilai debit sedimen metode Meyer Peter Muller.

2. Dari hasil perhitungan laju angkutan sedimen didapat volume kantong lumpur Bendung Air Musi Kejalo adalah 120 $\mathrm{m}^{3}$, sehingga dimensi kantong lumpur yaitu panjang $61 \mathrm{~m}$, lebar $4 \mathrm{~m}$, dan kedalaman 1,3 m. 
3. Dimensi kantong lumpur direncanakan berdasarkan nilai volume sedimen yang didapat dari nilai debit laju sedimen dan waktu pembilasan berasumsi selama 14 hari. Sehingga kantong lumpur perlu dibilas 14 hari sekali dengan cara pintu air pada saluran primer ditutup, kemudian pintu saluran pembilas dibuka, maka partikel yang berada pada kantong lumpur akan terbilas kembali kesungai.

4. Pada perencanaan dimensi kantong lumpur menggunakan konstruksi yaitu pasangan batu bulat dengan tipe saluran kantong lumpur berbentuk persegi dan tipe saluran induk berbentuk trapesium.

\section{DAFTAR PUSTAKA}

Badan Standardisasi Nasional, 1990. SNI 03-1968-1990 Metode Pengujian Analisis Saringan Agregat, Badan Standardisasi Nasional, Jakarta.

Badan Standardisasi Nasional, 2008. SNI 1964:2008 Cara Uji Berat Jenis Tanah, Badan Standardisasi Nasional, Jakarta.
Badan Standardisasi Nasional, 2015. SNI 8066:2015 Tata Cara Pengukuran Debit Aliran Sungai dan Saluran Terbuka Menggunakan Alat Ukur Arus dan Pelampung, Badan Standardisasi Nasional, Jakarta.

Direktur Jendral Pengairan, 1986. Kriteria Perencanaan 02 Bangunan Utama. Standar Perencanaan Irigasi, Departemen Pekerjaan Umum Direktorat Jenderal Pengairan. Penerbit PU. Jakarta.

Direktur Jendral Pengairan, 1986. Kriteria Perencanaan 03 Saluran. Standar Perencanaan Irigasi, Departemen Pekerjaan Umum Direktorat Jenderal Pengairan. Jakarta.

Google Earth. (Diakses: 12 Mei 2016, 09.00 WIB)

Yang, C. T., 1996. Sediment Transport, Krieger Publishing Company, Florid. 


\section{LAMPIRAN 1}

Bagan Alir Pelaksanaan Penelitian

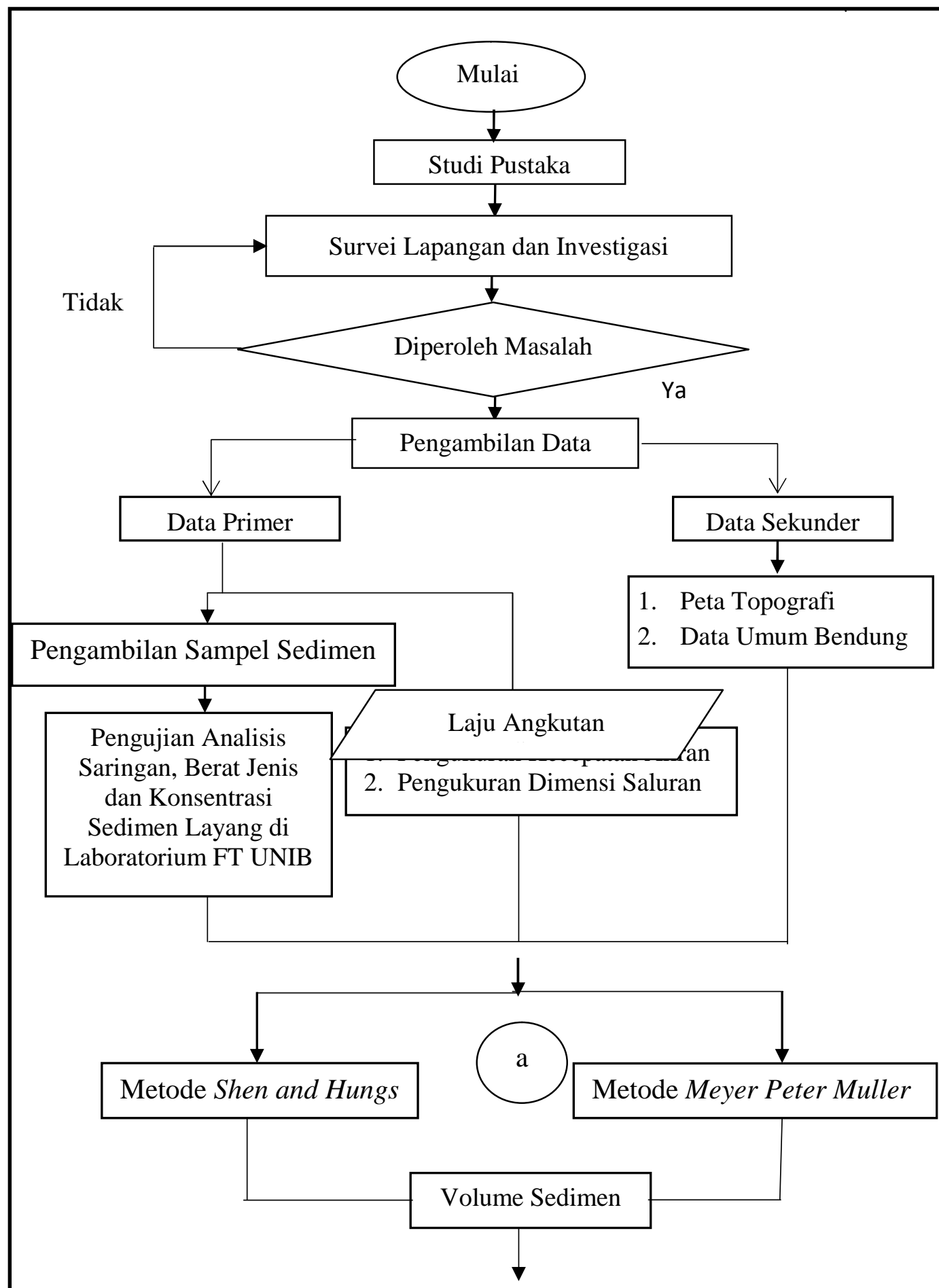




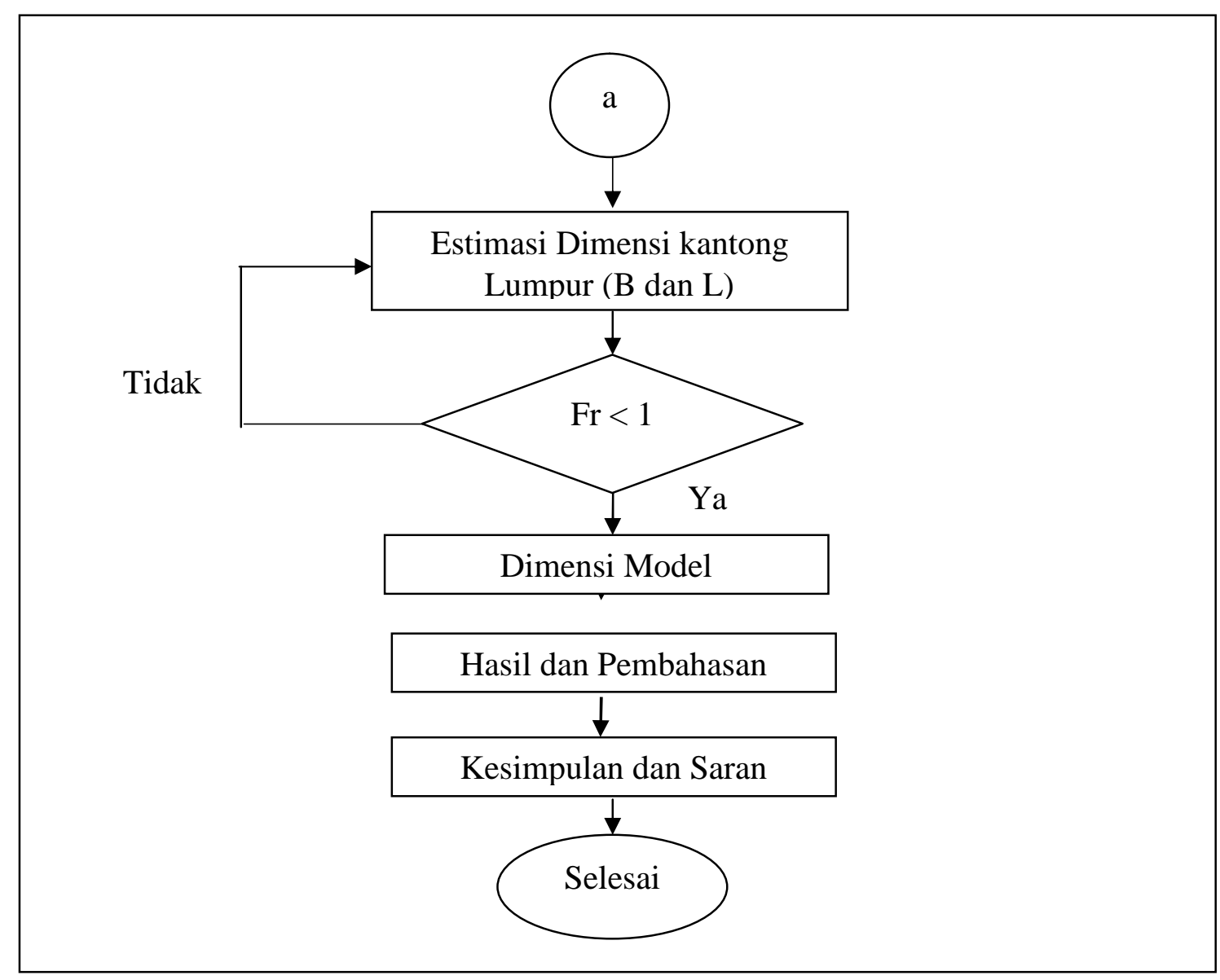

